\title{
Rekonstruksionalisme Pendidikan Formal sebagai Agen Utama dalam Tatanan Sosial
}

\author{
Amar Ma'ruf', Abd. Rochman Assegaf ${ }^{2}$ \\ Universitas Islam Negeri Sunan Ampel Surabaya, Indonesia \\ ${ }^{1}$ marufamar258@gmail.com, ${ }^{2}$ profassegaf@gmail.com
}

\begin{abstract}
Abstrak
Kedudukan pendidikan agama Islam sangat penting dan strategis dalam pelaksanaan pendidikan di setiap jenjang dan jenis pendidikan. Namun dalam realitasnya, pelaksanaan pendidikan agama Islam yang di selenggarakan oleh sekolah/ madrasah masih menuai permasalahan dan kritik dari berbagai pihak, untuk mengatasi segala kekurangan dan kelemahan praktek pendidikan agama Islam di lapangan, setidaknya harus ditempuh jalan perubahan. Untuk itu, dibutuhkan bangun dan kaji ulang melalui apa yang dinamakan rekonstruksi pendidikan agama Islam. Upaya tersebut dapat dilakukan melalui: pertama, menginterkoneksikan pendidikan agama Islam dengan pelajaran lain; kedua, melakukan atau menciptakan suasana religius di sekolah/ madrasah. Ilmu adalah sebuah pengetahuan yang harus dimiliki seorang. Ilmu di anjarkan kepada soerang atau anak didik diteliti oleh perguruan tinggi yang mana masyakat harus jugak berperan dalam pendidikan, pada masing-masing studi biasanya memiliki subdisiplin dan masing-masing sering kali bersifat buatan. kurikulumnya yang mana marketing oriented, bahkan hingga kenakalan para pelajar. Semua permasalahan atau problem itu seolah hanya ditumpah-ruahkan terhadap satu pihak, yakni tempat pendidikan, sambil seolah tidak menyadari bahwa dirinya pernah menjadi peserta didik di sana. Muncul rasa tidak puas terhadap kinerja pendidikan nasional.
\end{abstract}

Kata Kunci: rekonstruksionalisme, pendidikan formal, tatanan sosial 


\begin{abstract}
Education is a vehicle to actualize of the student's potential. The potential is always nurtured to be fully utilized in their life. The focus here is not to actualize in the form of exploitation, exertion and violence but it is directed to create a metamorphosis from the ordinary into the extraordinary. Yet, the word "metamorphosis" misinterpreted to another meaning as creating hard educational models for the students. It seems as cognitive educational activities which shows student's position as adult miniature. Here, the researcher will investigate the importance of discourse humanization as the concept of humanizing education. It's inspire to create a concept of Sekolah Ramah Anak to be applied in educational institutions so that students feel that education is appreciates their souls.
\end{abstract}

Keywords: reconstructionism, formal education, social order

\title{
PENDAHULUAN
}

Pendidikan sebagai agen tindakan merupakan proses yang sudah barang tentu dalam berfikir teoritik dan praktik. Keduanya perlu dipandang sebagai dua pandangan sisi mata uang yang hanya dapat dibedakan dengan saling berhubungan dan saling membutuhkan.

Aspek praktik atas pendidikan perlu mendapat perhatian yang cukup baik bagi pengembangan ilmu yang diperoleh maupun bagi peningkatan keberhasilannya dalam praktik. Teori pendidikan dikembangkan secara sistematis dengan memiliki ilmu dan pengetahuan sehingga diperoleh ilmu pendidikan sistematis dan fakta-fakta dari pendidikan yang telah lampau yang akan menghasilkan ilmu pendidikan historis. Ilmu pendidikan memiliki sifat komprehensif sehingga mengandung kemungkinan perkembangan yang cukup luas. ${ }^{1}$

\footnotetext{
${ }^{1}$ Imam Barnadib, Filsafat Pendidikan: SIstem Dan Metode (Yogyakarta: Andi Ofset, 1994), 2-3.
} 
Pada umumnya banyak ilmuwan yang meneliti tentang rekonstruksionalisme, namun saat ini penelitian ini mengacu pada rekotruksionalisme sebagai acuan masyarakat atau agen utama bagi tatanan masyarakat rekontruksionalisme mengatasi krisis kehidupan modern. Hanya saja jalan yang ditempuh berbeda, jika perenialisme memilih untuk kembali kepada kebudayaan lama yang telah teruji dan terbukti mampu membawa manusia mengatasi krisis sedangkan rekonstruksionalisme berusaha membina suatu konsensus yang paling luas dan paling mungkin mencapai tujuan utama dan tertinggi dalam kehidupan manusia untuk mencapai tujuan itu. Rekonstruksionalisme berusaha mencari kesepakatan semua orang mengenai tujuan utama yang dapat mengatur tata kehidupan manusia dalam suatu tatanan baru seluruh lingkungannya. Oleh karena itu, pada aliran rekonstruksionalisme ini, peradaban masa depan manusia sangat ditekankan. Rekonstruksionalisme menaruh perhatian terhadap pendidikan dalam kaitannya dengan masyarakat.

Kebanyakan manusia menilai bahwa praktik pendidikan dewasa ini masih jauh dari apa yang diharapkan. Mulai dari perekonomian, pendidikan mahal, guru yang tidak berkualitas, kurikulumnya yang mana menjadi marketing oriented, bahkan hingga kenakalan para pelajar. Semua problem yang ada itu seolah hanya ditumpah-ruahkan terhadap satu pihak, akan tetapi lembaga pendidikan, sambil seolah tidak menyadari bahwa dirinya pernah menjadi peserta didik di sana. Muncul rasa tidak puas terhadap perilaku peserta didik dalam dunia pendidikan nasional. Kata-kata ekstrimpun sering terluapkan bahwa pendidikan nasional telah gagal menjalankan misinya untuk membentuk insan-insan yang cakap dan 
berkepribadian serta membangun bangsa yang berkarakter dan beakhlak.

Namun pendidikan hanya bisa menghasilkan koruptor, kolutor, provokator, dan manusia-manusia tidak memiliki budi lainnya. Keadaan sekarang merupakan zaman yang atau global yang memiliki kebudayaan dan terpengaruh atas kehancuran, kebingungan dengan keragu-raguan. Demikianlah menurut perspektif beberapa pemikir yang menyatakan bahwa tradisi dan budaya modern telah mengalami kekurangan pengetahuan, sembari berusaha merombak mentata susunan lama dan membangun konsep baru mengenai pola hidup kebudayaan yang lebih dominan modern.

\section{HASIL DAN PEMBAHASAN}

Rekonstruksionalisme berasal dari kata reconstruct yang memiliki arti "menyusun kembali". Rekonstruksionalisme merupakan satu paham filsafat yang bertujuan melanjutkan gerakan progresivisme. Para kaum rekonstruksionis menentang para kaum progresif yang hanya berfokus dan melibatkan diri kepada masalahmasalah yang sekarang.

Filsafat rekonstruksionalisme juga merupakan elaborasi lanjutan dari gerakan progresivisme. Para kaum rekonstruksionis meyakini bahwa peradaban manusia masa depan sangat ditekankan. Mereka juga menekankan tentang perbedaan terhadap individual seperti kaum progresif, akan tetapi rekonstruksionalisme lebih menekankan terhadap pemecahan masalah, berpikir kritis dan sejenisnya.

Kaum rekonstruksionis juga memiliki perspektif bahwa masa depan suatu bangsa merupakan salah satu dunia yang diatur dan 
diperintah oleh rakyat secara demokratis, bukan dunia yang diatur atau dikuasai oleh golongan-golongan tertentu. Menurut manusia yang mempunyai kekuasaan punya cita-cita demokrasi yang sesungguhnya tidak hanya dalam teori, akan tetapi harus diwujudkan menjadi kenyataan, dan tidak hanya mempunyai kuantitas, tapi dapat meningkatkan kualitas kesehatan, kesejahteraan, kemakmuran, serta keamanan di tengah masyarakat, tanpa ada perbedaan-perbedaan terhadap warna kulit, keturunan, nasionalisme, agama (kepercayaan) dan masyarakat yang bersangkutan dalam mengelola pendidikan.

\section{Rekontruksionalisme Pendidikan}

Aliran rekonstruksionalisme merupakan suatu aliran yang berusaha merombak tata susunan yang lama dengan membangun tata susunan hidup kebudayaan yang mengacu modern. Aliran rekonstruksionalisme pada prinsipnya sepemikiran dengan aliran perenialisme, yaitu berawal dari krisis kebudayaan modern. Menurut Muhammad Noor Syam, kedua aliran tersebut memandang bahwa keadaan sekarang merupakan zaman yang mempunyai kebudayaan yang terganggu oleh kehancuran, kebingungan dan kesimpangsiuran. Walaupun demikan, pemikiran yang dimiliki oleh aliran ini tidaklah sama dengan prinsip yang dipegang oleh aliran filsafat perenialisme. Keduanya mempunyai tujuan dan cara yang berbeda dalam pemecahan yang akan ditempuh untuk mengembalikan kebudayaan yang serasi dalam kehidupan. ${ }^{2}$ Sementara menurut Imam Barnadib, rekonstruktivisme sebagai filsafat pendidikan menghendaki peserta didik yang mencari pengetahuan agar dibangkitkan kemampuannya

\footnotetext{
${ }^{2}$ Siti Fatimah, "Merekonstruksi Pembelajaran Pendidikan Agama Islam dan Budi Pekerti di Sekolah Negeri Studi Kasus SMAN 14 Yogyakarta," el-Tarbawi 11, no. 1 (2018): 14.
} 
untuk secara rekonstruktif menyesuaikan diri dengan tuntutan perubahan dan perkembangan masyarakat, sebagai akibat adanya pengaruh dari ilmu pengetahuan dan teknologi. ${ }^{3}$

Sirkulasi rekonstruksionalisme merupakan suatu aliran yang berusaha merombak tata susunan lama dan membentuk tata hidup kebudayaan yang menjawab permasalahan-permasalahan global modern. Sirkulasi rekonstruksionalisme, pada prinsipnya, sepaham menggunakan aliran perenialisme, yaitu hendak melampaui krisis kebudayaan modern. Kedua aliran tersebut, aliran rekonstruksionalisme dan perenialisme, memandang bahwa zaman modern merupakan zaman yang tatanan sosialnya terganggu oleh kehancuran, kebingungan dan kesimpangsiuran. Walaupun demikian, prinsip yg dimiliki oleh aliran rekonstruksionalisme tidaklah sama dengan prinsip yang dipegang oleh aliran perenialisme. Keduanya memiliki visi dan cara yg tidak sinkron dalam pemecahan yang akan ditempuh untuk mengembalikan kebudayaan. ${ }^{4}$

Muhammad Iqbal dalam Rahmayana menyebutkan bahwa pendidikan rekonstruksionalisme memiliki keinginan pedidikan yang sesuai dengan pemikiran manusia yakni suatu pendidikan yang mengaksentuasikan kegiatan pada pemberian pengetahuan kepada subjek didik melalui metode problem solving, suatu cara yang benar untuk melatih berpikir kreatif, kritis, dan inovatif. Dengan cara ini menurutnya dapat membentuk cakrawala berpikir subjek anak didik

\footnotetext{
${ }^{3}$ Barnadib, Filsafat Pendidikan: SIstem Dan Metode, 12.

4 Nurul Qomariyah, "Pendidikan Islam Dan Aliran Filsafat Pendidikan Rekonstruksionalisme," Al-Falah: Jurnal Ilmiah Keislaman dan Kemasyarakatan 17, no. 2 (2017): 22.
} 
sedemikian rupa sehingga menjadi manusia-manusia yang memiliki sikap tegap terhadap berbagai problematika kehidupannya. ${ }^{5}$

Namun, Arthur K. Ellis menganggap rekonstruksionalisme merupakan perkembangan atas progresivisme dalam pendidikan yang kadang kala mengartikan sebagai rekonstruksi sosial. Pengikut aliran rekonstruksionalisme, lanjutnya, pada dasarnya menganggap bahwa progresivisme hanya memerhatikan problematika masyarakat pada saat itu saja (sedang dihadapi), padahal yang diperlukan di abad kemajuan teknologi yang berperang aktif demikian cepat ini adalah upaya rekonstruksi masyarakat atas penciptaan tatanan dunia baru secara menyeluruh. Di antara para pendukung aliran ini adalah John Dewey. Secara jelas, kecenderungan Dewey pada rekonstruksionalisme dapat dlihat dari pernyataannya. ${ }^{6}$

Pertama, rekonstruksionalisme menjelaskan akhir (akibat atau hasil) dan proses. Artinya, pendidikan dalam rekonstruksionalisme tidak identik dengan ketidakpastian arah atau tujuan dan tanpa melalui proses. Meskipun rekonstruksionalisme menganggap bahwa pengetahuan pengalaman itu mengalami perkembangan dan perubahan, tidak berarti pendidikan yang diselenggarakan kehilangan arah dan tujuan. Kedua, pengalaman dan kegiatan secara terus menerus berkembang dan berubah, sejajar dan tuntutan yang dihadapi oleh pendidikan pada saat itu (di sini rekonstruksionalisme berjangkauan lebih jauh dari progresivisme). Ketiga, konstruksi pengalaman itu bisa terjadi baik pada individu peserta maupun kolektif. Konsekuensinya, pendidikan mesti memperhatikan kedua

\footnotetext{
${ }^{5}$ Jeeny Rahmayana, "Filsafat Rekonstruksionisme Dalam Pendidikan Islam Studi Atas Pemikiran Muhammad Iqbal,” Jurnal Tamaddun Ummah 1, no. 1 (2015): 15.

${ }^{6}$ Siti Nur Zakiyah, "Pengembangan Sekolah Ramah Anak Berbasis Edutainment Di SD Muhammadiyah 1 Purbalingga" (IAIN Purwokerto, 2017), 35.
} 
aspek tersebut. Selanjutnya, Dewey menyatakan bahwa pendidikan ialah rekonstruksi atau reorganisasi pengalaman hingga mampu menambah makna pengalaman tersebut, serta dapat meningkatkan kemampuan untuk menentukan arah pada pengalaman berikutnya. ${ }^{7}$

Secara praktis, rekonstruksionalisme dalam pendidikan memiliki tujuan pendidikan adalah peningkatan kesadaran peserta didik mengenai problematika sosial, politik serta ekonomi yang dihadapi oleh manusia secara modern, dan mendapatkan pembinaan dan membekali mereka dengan kemampuan-kemampuan dasar agar bisa menyelesaikan problem-problem tersebut. Kurikulum dan metode atau model pendidikan menurut rekonstruksionalisme haruslah mencakup muatan sosial, politik, dan ekonomi yang sedang dihadapi oleh masyarakat, termasuk juga masalah-masalah pribadi yang dihadapi oleh peserta didiknya. Sementara itu metode dalam kurikulum rekonstruksionis menggunakan disiplin ilmu-ilmu sosial dan metode ilmiah. ${ }^{8}$

Adapun corak aktivitas pembelajaran pada aliran rekonstruksionalisme menurut Kinsley Price yaitu: a) segala sesuatu yang bercorak otokrasi mesti dihindari, sehingga yang belajar terhindar dari unsur pemaksaan, b) guru harus bisa meyakinkan peserta didiknya akan kemampuannya dalam memecahkan masalah, sehingga masalah yang ada dalam subject matters dapat diatasi, c) untuk menumbuhkan dan meningkatkan keinginan belajar peserta didik, seorang guru harus mampu mengenali peserta didik secara individu, d) seorang guru harus bisa menciptakan kondisi kelas

\footnotetext{
7 Herlini Puspika Sari, "Rekonstruksionisme Pendidikan Islam Menurut Muhammad Iqbal," Al-Fikra: Jurnal Ilmiah Keislaman 19, no. 1 (2020): 25.

${ }^{8}$ Aren Njuk, "Pengaruh Kreativitas Guru Terhadap Motivasi Belajar Siswa PAUD Bunga Bakung Long Aran,” 2018, 20.
} 
sedemikian rupa sehingga interaksi guru dengan peserta didik dan semua yang hadir dalam satu ruangan kelas dapat berkomunikasi dengan baik, tanpa ada yang menunjukkan sikap otoriter. ${ }^{9}$

Dari pemaparan di atas dapat disimpulkan bahwa rekonstruksi pendidikan mempunyai tujuan khusus yaitu untuk meningkatkan kesadaran peserta didik mengenai problematika sosial, politik dan ekonomi yang dihadapi oleh manusia secara global, dan untuk membina peserta didik, membekali mereka dengan kemampuankemampuan dasar agar bisa menyelesaikan persoalan- persoalan tersebut.yang serasi dalam kehidupan.

Maka, proses dan lembaga pendidikan dalam pandangan rekonstruksionalisme perlu mentata ulang susunan lama dan membangun tata kelola yang baru. Untuk mencapai tujuan utama tersebut diperlukan time dan kerjasama antara seluruh elemen umat manusia. Aliran rekonstruksionalisme berkeyakinan bahwa tugas penyelamatan dunia merupakan tugas kemanusiaan yang menjadi tanggungjawab semua bangsa dan individu. Karenanya pembinaan kembali daya intelektual dan spiritual yang sehat dapat diwujudkan melalui pendidikan yang tepat atas nilai-nilai dan norma yang benar, sehingga terbentuk tatanan dunia modern yang harmonis. ${ }^{10}$

\section{Rekontruksionalisme Pendidikan formal}

Sekolah-sekolah yang merefleksikan nilai-nilai sosial dominan, menurut rekonstruksionis hanya akan mengalihkan penyakit-penyakit politik, sosial, dan ekonomi yang sekarang ini mendera umat

\footnotetext{
9 Jalaluddin and Abdullah Idi, Filsafat Pendidikan: Manusia, Filsafat Dan Pendidikan (Jakarta: Rajawali Pers, 2018), 40.

${ }^{10}$ Rini Puspitasari, "Pendidikan Islam Menurut Muhammad Iqbal," Manhaj: Jurnal Penelitian dan Pengabdian Masyarakat 6, no. 3 (2017): 13.
} 
manusia. Sekolah dapat dan harus mengubah secara mendasar peran tradisionalnya dan menjadi sumber inovasi sosial. ${ }^{11}$

Adapun tugas mengubah, peran pendidikan sangatlah urgen, karena kenyataan bahwa manusia sekarang mempunyai kemampuan memusnahkan diri. Kritik-kritik rekonstruksi sosial menandaskan bahwa Brameld dan kolega-koleganya memberikan kepercayaan yang sangat besar terhadap kekuatan seorang pengajar (guru) dan pendidik lainnya untuk memberi tindakan sebagai instrumen utama perubahan sosial.

Komentar kalangan rekonstruksionis bahwa satu-satunya alternatif bagi rekonstruksi sosial adalah kekacauan global dan kemusnahan menyeluruh peradaban manusia. Dari pola pikir mereka, pendidikan dapat menjadi instrumen untuk mengaburkan tuntutan mendesak transformasi sosial dan kemudian memberikan perubahan, atau instrumen untuk membentuk keyakinan masyarakat dan mengarahkan peralihannya ke masa depan. Kalangan rekonstruksionis di satu sisi tidak memandang sekolah memiliki kekuatan untuk menciptakan perubahan sosial.

Di sisi lain mereka memandang sekolah sebagai agen kekuatan utama yang menyentuh kehidupan seluruh masyarakat, karena sekolah menyantuni peserta didik selama usia mereka yang paling peka. Dengan demikian lembaga atau sekolah bisa menjadi penggerak utama pencerahan problem-problem sosial dan agitator utama perubahan sosial.

Mengenai kurikulum pendidikan, rekonstruksionalisme beranggapan sebagai subjek matter yang berisikan masalah-masalah sosial, ekonomi, politik yang beraneka ragam, yang dihadapi umat

\footnotetext{
${ }^{11}$ Jalaluddin and Idi, Filsafat Pendidikan: Manusia, Filsafat Dan Pendidikan, 19.
} 
manusia, termasuk problem-problem sosial dan pribadi terdidik itu sendiri. Isi kurikulum tersebut berguna dalam penyusunan disiplin "sains sosial" dan proses penemuan ilmiah (inkuiri ilmiah) sebagai model kerja untuk memecahkan masalah-masalah sosial.

\section{Rekontruksionalisme sebagai Agen Utama dalam Tatanan Sosial Masyarakat}

Persoalan-persoalan yang ada di masyarakat, sumber daya alam yang terbatas, kesenjangan global dalam distribusi (penyebaran) kekayaan, proliferasi nuklir, rasisme, nasionalisme sempit, dan penggunaa teknologi yang tidak bertanggung jawab telah mengancam dunia dan akan menghilangkanya jika tidak dikoreksi sesegera mungkin. Persoalan-persoalan tersebut menurut kaum rekonstruksionis berjalan seiring dengan tantangan totalitarianisme modern, yakni hilangnya nilai-nilai kemanusiaan dalam masyarakat luas dan meningkatnya kebodohan fungsional penduduk dunia. Singkatnya dunia sedang menghadapi problem atau persoalan persoalan sosial, militer dan ekonomi pada skala yang tak terbayangkan. Persoalan-persoalan yang dihadapi sudah sedemikian beratnya sehingga tidak bisa lagi diabaikan.

Mengingat persoalan-persoalan yang bersifat mendunia, maka memberikan solusinya pun harus demikian. Kerjasama menyeluruh dari semua bangsa adalah satu-satunya harapan bagi penduduk dunia yang berkembang terus yang menjadi penghuni dunia dengan segala keterbatasan sumber daya alamnya. Era teknologi telah memunculkan saling ketergantungan dunia, di samping juga kemajuan-kemajuan di bidang sains. Di sisi lain, terdapat masalah yang sedang mendera yaitu kesenjangan budaya dalam beradaptasi dengan tatanan dunia 
baru. Menurut rekonstruksionalisme, saat ini umat manusia hidup dalam masyarakat dunia yang mana kemampuan teknologinya dapat membinasakan kebutuhan-kebutuhan material semua orang.

Dalam masyarakat ini, sangat mungkin muncul "penghayale karena komunitas internasional secara bersama-sama bergelut dari kesibukan menghasilkan dan mengupayakan kekayaan material menuju ke tingkat yang mana kebutuhan dan kepentingan manusia dianggap paling penting. dengan dunia semacam itu, orang-orang selanjutnya berkonsentrasi untuk menjadi manusia yang lebih baik (secara material) sebagai tujuan akhir.

\section{Pendidikan Formal sebagai Agen Utama dalam Tatanan Sosial}

Sekolah-sekolah yang merefleksikan nilai-nilai sosial dominan, menurut rekonstruksionis hanya akan mengalihkan penyakit-penyakit politik, sosial, dan ekonomi yang sekarang ini mendera umat manusia. Sekolah dapat dan harus mengubah secara mendasar peran tradisionalnya dan menjadi sumber inovasi sosial. Tugas mengubah peran pendidikan sangat urgen, karena kenyataan bahwa manusia sekarang mempunyai kemampuan memusnahkan diri. Kritik-kritik rekonstruksi sosial menandaskan bahwa Brameld dan kolegakoleganya memberikan kepercayaan yang sangat besar terhadap kekuatan seorang pendidik dan pendidik lainnya untuk bertindak sebagai instrumen utama perubahan sosial.

Komentar kalangan rekonstruksionis bahwa satu-satunya alternatif bagi rekonstruksi sosial adalah kekacauan global dan kemusnahan menyeluruh peradaban manusia. Dari perspektif mereka, pendidikan dapat menjadi instrumen untuk mengaburkan tuntutan mendesak transformasi sosial dan kemudian merintangi perubahan, 
atau instrumen untuk membentuk keyakinan masyarakat dan mengarahkan peralihannya ke masa yang akan datang. Kalangan rekonstruksionis dalam satu sisi tidak memandang sekolah memiliki kekuatan untuk meberikan dan menciptakan perubahan sosial.

Di sisi lain mereka memandang sekolah sebagai agen kekuatan utama yang menyentuh kehidupan seluruh masyarakat, karena sekolah menyantuni anak-anak didik selama usia mereka yang paling peka. Dengan demikian sekolah bisa menjadi penggerak utama pencerahan problem-problem sosial dan agitator utama perubahan sosial.

Pada prinsipnya filsafat rekrontruksionisme berupaya mencari kesepakatan antara sesama manusia agar dapat mengatur tata kehidupan manusia dalam suatu tatanan dan seluruh lingkungannya, oleh karenanya pendidikan perlu merombak tata susunan lama dan membangun tata susunan hidup kebudayaan yang baru, sehingga perlu kerjasama antar umat manusia.

Para tokoh pendidikan Islam telah banyak membahas, tentang pondasi pendidikan dalam Islam terutama filsafat sebagai konsep dasar maju mundurnya suatu pendidikan. Telah menjadi mafhum bersama bahwa keadaan masyarakat Islam di berbagai tempat dan negeri mengalami berbagai problem dan permasalahan budaya, ekonomi, sosial dan politik. Hal ini disebabkan karena kaum muslimin tidak melaksanakan dengan sempurna ajaran-ajaran dan hukum-hukum agama dalam semua urusan kehidupannya. Begitu juga disebabkan keterbelakangan pemikirannya, melupakan pendidikan, dan mengikuti orang lain dalam segala hal. ${ }^{12}$

\footnotetext{
12 Ali Musa Lubis, "Konseling Islami Dan Problem Solving," Ri'ayah: Jurnal Sosial dan Keagamaan 1, no. 2 (2016): 110.
} 


\section{KESIMPULAN}

Pendidikan dalam rekonstruksionalisme menghendaki agar peserta didik mampu menyesuaikan diri dengan tuntutan perubahan dan perkembangan masyarakat sebagai akibat adanya pengaruh dari ilmu pengetahuan dan teknologi. Asumsi dasar dalam rekonstruksionalisme adalah hipotesis bahwa masyarakat dunia sedang dalam kondisi kritis multidimensi.

Aliran rekonstruksionalisme adalah suatu aliran yang menangani sebuah permaslahan atau cara peneyelesaian problem yang dimiliki oleh pendidik dan masyarakat dan begitu juga rekontruksionalisme adalah sebagai agen utama dalam pendidikan yang tidak lepas dengan kurikulum yang telah dibuat oleh negara. Pada prinsipnya, sepaham dengan aliran perenialisme, yaitu hendak melampaui krisis kebudayaan modern. Dan agen utama sosial masyrakat atau penduduk sekitar.

\section{DAFTAR PUSTAKA}

Barnadib, Imam. Filsafat Pendidikan: SIstem Dan Metode. Yogyakarta: Andi Ofset, 1994.

Fatimah, Siti. "Merekonstruksi Pembelajaran Pendidikan Agama Islam Dan Budi Pekerti Di Sekolah Negeri Studi Kasus SMAN 14 Yogyakarta." el-Tarbawi 11, no. 1 (2018).

Jalaluddin, and Abdullah Idi. Filsafat Pendidikan: Manusia, Filsafat Dan Pendidikan. Jakarta: Rajawali Pers, 2018.

Lubis, Ali Musa. "Konseling Islami Dan Problem Solving." Ri'ayah: Jurnal Sosial dan Keagamaan 1, no. 2 (2016).

Njuk, Aren. "Pengaruh Kreativitas Guru Terhadap Motivasi Belajar Siswa PAUD Bunga Bakung Long Aran,” 2018.

Puspitasari, Rini. "Pendidikan Islam Menurut Muhammad Iqbal." Manhaj: Jurnal Penelitian dan Pengabdian Masyarakat 6, no. 3 (2017). 
Qomariyah, Nurul. "Pendidikan Islam Dan Aliran Filsafat Pendidikan Rekonstruksionisme." Al-Falah: Jurnal Ilmiah Keislaman dan Kemasyarakatan 17, no. 2 (2017).

Rahmayana, Jeeny. "Filsafat Rekonstruksionisme Dalam Pendidikan Islam Studi Atas Pemikiran Muhammad Iqbal." Jurnal Tamaddun Ummah 1, no. 1 (2015).

Sari, Herlini Puspika. "Rekonstruksionisme Pendidikan Islam Menurut Muhammad Iqbal.” Al-Fikra: Jurnal Ilmiah Keislaman 19, no. 1 (2020).

Zakiyah, Siti Nur. "Pengembangan Sekolah Ramah Anak Berbasis Edutainment Di SD Muhammadiyah 1 Purbalingga." IAIN Purwokerto, 2017. 
Amar Ma'ruf, Abd. Rochman Assegaf | MAHAROT Vol. 5, No. 2, 2021 